\title{
Discussion on the Logical Basis of Critical Thinking
}

\author{
Shi Jing \\ School of Culture and Media, Central University of Finance and Economics, Beijing, China
}

\section{Email address:}

shijing0707@163.com

\section{To cite this article:}

Shi Jing. Discussion on the Logical Basis of Critical Thinking. International Journal of Philosophy. Vol. 9, No. 2, 2021, pp. 100-105. doi: $10.11648 /$ j.ijp. 20210902.14

Received: April 26, 2021; Accepted: May 11, 2021; Published: May 20, 2021

\begin{abstract}
Theoretically, critical thinking has a close connection with logic science. It is only a matter of opinion whether critical thinking should be used to direct the science of logic or it should be based on logic science. Many scholars, including educators, psychologists, and philosophers have joined in the discussion on critical thinking. There are two main viewpoints on the Basis of Critical Thinking. As a foundation course based on science, the science of logic curriculum is well-developed and mature. The science of logic can be subdivided into formal logic and informal logic. One of them believes that critical thinking has nothing to do with logic science, while the other argues that critical thinking is interrelated with both branches of formal and informal logic, but it is different from both of them. What' $\mathrm{s}$ more, it holds that formal logic and informal logic together constitute the logical basis of critical thinking. In addition, as a form of thinking, critical thinking and innovative thinking are closely related to logical thinking and contain logical thinking. Therefore, innovative thinking is the purpose of critical thinking, and logic is the theoretical basis of critical thinking. The cultivation of critical thinking and innovative thinking is conducive to the cultivation of College Students' innovative quality and spirit, and to the improvement of the cultivation quality of innovative talents.
\end{abstract}

Keywords: Critical Thinking, Informal Logic, Formal Logic, Relationship

\section{Introduction}

At present, Chinese universities that offer critical thinking courses all directly use the science of logic as the basis of critical thinking curriculum. In China, people who are interested in critical thinking discussions are mostly engaged in logic education. This in essence gives rise to the discussion of relationship between critical thinking and logic science. Some Chinese scholars believe that "informal logic" depends on logic after all, no matter what you can quote from the connotation of the antonym prefix "in". "Critical thinking", on the other hand, is different: it does not need to deal with the problem caused by the antonym prefix "in" and there is even no need for it to consider logic problem. Therefore, in the opinion of these scholars, "critical thinking" is not within the realm of logic science, or at least it may be possible to say so. In my opinion, to answer this question accurately, we must first of all accurately understand the meaning of logic science. As a branch of science, logic science takes reasoning and argumentation as its object of study. Its main task is to study the validity of reasoning forms, to provide criteria for identifying effective reasoning and ineffective reasoning, and to teach people how to reason and argue in a correct way, as well as to identify, expose and refute incorrect reasoning and argumentation. Additionally, we have to know critical thinking. Critical thinking should not only solve the problem concerning the validity of reasoning form, but also answer the question on the authenticity and credibility of reasoning premise. That is to say, critical thinking is concerned with both the form and content of thinking, which is the basic feature of daily thinking. The very core of critical thinking is identifying, evaluating and reconstructing argumentation. Its main concern is the authenticity and credibility of arguments, that is, the correlation between arguments and arguments in respect of the content. As a thinking skill and strategy, critical thinking must take the general rules of formal logic as its basis and premise. To make a strict distinction between the effective reasoning form and the invalid reasoning form in formal logic is indispensable for accurate critical thinking: an argument based on invalid reasoning form is not convincing, and a persuasive argument can only be born of the effective reasoning form. Therefore, we can not confuse critical 
thinking with informal logic. At best, we may say that informal logic provides the logical basis for critical thinking. In other words, logic science is the theoretical basis of critical thinking.

Theoretically, I agree with Coon \& Mitterer on the definition of Critical Thinking put forward in 1995. It emphasizes that critical thinking is basically the thinking ability to identify truth by discarding falsehood. It is also the capacity to critically evaluate, compare, analyze, and integrate different kinds of information which are often mixed together. Critical thinking can help make people rational, objective and wise, and thus give birth to truly independent thinking [1]. Besides, critical thinking should at least have the following characteristics: first of all, it is a tendency or skill to engage in activities; secondly, it is a mental activity with skepticism to decide what to believe or what to do; finally, it can be proved.

The purpose of introducing this topic for discussion is to share my viewpoint on the relationship between critical thinking and logic science. What is the basis of critical thinking? I hope to grasp the basis of critical thinking through the discussion of their relationship, and promote the discussion of critical thinking to a wider sphere and more and more people will join in the discussion.

\section{The Relationship Between Critical Thinking and Informal Logic}

At present, many famous universities in China have offered critical thinking courses on the basis of logic, and have achieved good teaching results. But what is the relationship between critical thinking and logic? Is the logical basis of critical thinking merely informal logic? These are issues that need special attention.

Gerde proposed that informal reasoning is the central component of critical thinking [2]. And informal reasoning is one of the main contents of informal logic. According to Scriven, informal logic focuses on the analysis of critical thinking skills [3]. Therefore, critical thinking is closely related to informal logic. Perhaps just based on this reason, Canada established the Association for Informal Logic and Critical Thinking (AILACT) in 1983. According to Facione's framework of critical thinking skills, we can see that informal logic and critical thinking do have similarities and differences. In his opinion, critical thinking skills include interpretation, analysis, evaluation, inference, explanation and self-regulation [4]. (1) "Interpretation" refers to the cognitive skills used to clarify and express the significance or importance of different experiences, situations, data, events, judgments, customs, beliefs, rules, procedures or standards. It includes at least the following seven hows: How to identify or describe a problem without prejudice? How to grasp a person's intention in his expression? How to distinguish the main viewpoint from the minor viewpoint in the text? How to construct a tentative classification organization or organization method for what you are studying? How to explain other people's viewpoints in your own words? How to clarify the meanings of symbols, tables or graphics? How to identify the author's purpose, theme or viewpoint? And so on.(2)"Analysis" refers to cognitive skills used to identify the purposeful inferential relationships between statements, questions, concepts, descriptions or other forms of expression that attempt to express beliefs, judgments, experiences, reasons, information or opinions. This skill includes examining viewpoints, identifying arguments and analyzing arguments.(3)"Evaluation" means firstly evaluating the credibility of statements or other expressions. which statement or expression is used to explain or describe a person's perception, experience, situation, judgment, belief or viewpoint, and secondly evaluating the logical strength of purposeful inferential relationships in statements, descriptions, questions or other forms of expressions. (4)"Inference" refers to firstly the essential elements for identifying and protecting reasonable conclusions; secondly considering relevant information; and thirdly deriving results from data, statements, principles, evidence, judgments, beliefs, opinions, concepts, descriptions, problems or other forms of expressions. It includes three sub-cognitive skills: cross-examination, speculation and conclusion.

With these four skills above, people can explain what a person is thinking and how to reach a judgment. But how can we apply the power of critical thinking to ourselves in order to improve our previous views? This requires two others kills, namely, explanation and self-regulation. (5)"Explanation" means firstly stating the result of one's reasoning; and secondly proving that reasoning according to the considerations of evidence, concepts, methods, standards and background, on which the result depends. This skill includes presenting results, proving procedures and coming up with arguments.(6)"Self-regulation" refers to the conscious monitoring of one's own cognitive activities and the elements and outcomes used in these cognitive activities, especially the skills used in the analysis and evaluation of one's own reasoning evaluation by questioning, confirming, confirming or correcting one's own reasoning or the reasoning outcomes. This skill includes the two types: self-examination and self-correction. Maybe most people have these six cognitive skills, but as long as they don't make full use of them to think, they can't say they have critical thinking.

According to Ralph H. Johnson and John A. Blair, editor-in-chief of the magazine Informal Logic, Informal Logic is a branch of logic. Its task is to describe the informal criteria, measurement and procedures of argumentation analysis, argumentation interpretation, argumentation evaluation, argumentation criticism and argumentation construction in our daily life [5]. Argumentation theory, argumentation analysis, argumentation evaluation and argumentation criticism are four related fields in informal logic that need to be studied. Thus it can be seen that "informal logic" and "critical thinking" are both aimed at the argumentation of natural language in our daily life. Therefore, Fisher and Scriven define informal logic as a discipline whose central task is to study the practice of critical thinking and provide intelligence power [6]. Cui Qingtian and Wang 
Zuoli believe that although both of them take empirical and practical argumentation expressed in natural language as their objects, informal logic is logic after all. It takes the identification, extraction and construction of the general process and form of practical argumentation as its barycenter and base point, while critical thinking focuses on argumentation from multiple perspectives and critically [7]. We can not equate critical thinking with informal logic, because if so, we will limit informal logic to a narrow range, and likewise, we limit critical thinking to a narrow range. In other words, critical thinking and informal logic are interrelated rather than inclusive. Obviously, we can not equate critical thinking with informal logic. At most it can be said that informal logic provides a logical basis for critical thinking.

\section{The Relationship Between Critical Thinking and Formal Logic}

As the logical basis of critical thinking, informal logic is not the only one, because formal logic also plays an important role in the process of critical thinking. However, when we study the current foreign critical thinking textbooks, it is not difficult to find that people tend to ignore formal logic, and ignore the formal characteristics of reasoning associated with mathematical and natural science reasoning methods. Paul not only neglected formal logic, but also sometimes openly opposed all formal methods. $\mathrm{He}$ recommended the use of "argumentative analysis" to replace the formal method of argumentative analysis. Kerry Wallers also accused critical thinking of being too absolute and simplified in its analysis. He points out that in the classical critical thinking course, "people tend to restore argumentation to its simplest constituent elements, check the truth of these elements individually or check their logical form one by one, and then decide whether the argumentation is good or bad". He believed that this was actually an unacceptable procedure. Both Paul and Walters believed that the complexity of life would not allow for analysis by means of formal logic techniques. Their reasons are as follows, firstly, most of the arguments people encounter in daily life are not direct examples of effective arguments; secondly, because formal logic with symbols and formulas is more like mathematics, critical thinking textbooks try to avoid using symbols in large quantities; and thirdly, traditional logic courses seldom teach students the ability to deal with reasoning and argumentation in our daily life. Some members of the critical thinking movement always want to expel symbols as much as possible and abandon the systematic treatment of symbolic logic. The analysis of such important concepts as "logical form" and "deduction", either absent or visualized, depends entirely on the ability of people to imagine the counterexamples of the arguments discussed, which only quite a small number of people possess. Therefore, in order to achieve universal acceptance of critical thinking, informal methods do have its advantages. If the two concepts of critical thinking and informal logic are used indiscriminately, not only psychologists and educators disagree, but I am afraid that even philosophers may disagree either.

Just as informal logic does not exclude formal logic, critical thinking can not exclude formal logic, on the contrary, it should be based on formal logic. We believe that the purpose of critical thinking is to let students learn to evaluate their beliefs or others' beliefs before starting a certain behavioral process [8]. The first step in this evaluation is to find out what this belief is and what reasons or evidence it gives to support it. The evaluation of beliefs is actually the argument evaluation of beliefs. Evaluation of arguments are relatively complex. It involves hidden presuppositions or assumptions, the discovery of many unclear or ambiguous terms, and the need to find out whether the premises are sufficient to support the conclusions of certain methodologies. People engaged in evaluation must have criteria for evaluation so as to be able to distinguish "good argument" from "bad argument". There are four criteria for evaluating the quality of argumentation, such as personal feelings and intuitions; cultural norms of the issues being discussed; methods of informal logic; and methods of formal logic. Obviously, personal feelings and intuitions, as well as cultural norms, can not provide a sufficient standard to evaluate the argument. It seems that there are only three possible choices left: the method of informal logic, the method of formal logic, and the synthesis of the method of informal logic and the method of formal logic. Practice has proved that the method of formal logic alone is impossible. The rise of informal logic fully proves this point.

The question now is whether the course of critical thinking should absorb both formal logic and informal logic, or only informal logic. In order to distinguish good argument from bad argument, the method of formal logic has many things to commend. First, some concepts used by formal logicians, such as reliability, deduction and validity, have been clearly defined. The nearest to the best form of argument is the deductive argument, because as long as the premise is true, its conclusion must be true. From the point of view of the good degree of argumentation, deductive argumentation is the best, inductive argumentation comes the second. Secondly, logic is about the science of argumentation, which includes formal logic and informal logic. Almost all works on critical thinking written by philosophers or logicians are about the reasoning or argumentation. For example, Robert Cogen's book Critical Thinking: Step by Step is divided into three parts: reasoning analysis, reasoning evaluation and evaluation of unsupported beliefs. The first part is the content that informal logic focuses on, while the second part is the content which formal logic investigates. In the second part of the book, the basic concepts of evaluation of argument introduced are reliability, truth value and validity. These three concepts are the very basic concepts of formal logic [9]. As another example, the book Introduction to Logic and Critical Thinking by Merrilee Salmon comprehensively and systematically introduces the relationship between logic and 
critical thinking. This book is written on the definition that logic focuses on the science of argumentation. He divides argumentation into deductive argumentation, inductive argumentation and fallacious argumentation. Actually in other words, he claims that the logical basis of critical thinking is deductive logic, inductive logic and informal logic. Thus, the importance of formal logic to critical thinking can be seen. To sum up, critical thinking and logic are inextricably linked. In other words, logic is the theoretical basis of critical thinking, or the logical basis of critical thinking is logic. However, it must be noted that the "logic" here refers not only to the traditional "logic with narrow sense", that is, formal logic, but also to the "logic with broad sense" including informal logic. This can also be proved by the website, On Debate and Critical Thinking, launched by Humboldt State University in the United States, which aims to help the contemporary college students improve their critical thinking ability. The purpose of this website is to help college students learn the basic concepts of the formal logic structure argued and informal fallacy of argumentation. The website launches a test of the guide On Debate and Critical Thinking, which covers traditional logic syllogism, propositional reasoning, Toulmin model, informal fallacies and so on. That is to say, these tests cover both informal logic and formal logic. Therefore, it is essential to understand the essence of logical deduction for providing criteria for evaluation of argumentation, and it is necessary to absorb the basic methods and some results of formal logic.

\section{The Relationship Between Critical Thinking and Innovative Thinking}

"Innovation" can be understood as discovering the defects of old theories, technologies and products, proposing new problems to be solved, and then proposing new ideas, technologies and methods to create new theories, technologies or products. Obviously, there is a close relationship between critical thinking and innovation, which plays an important role in the process of innovation. There is a misunderstanding of critical thinking that it conflicts with innovation. This view holds that innovation means manufacturing and generation, while critical thinking is essentially qualitative, which can only be used to find defects and deficiencies. Its emphasis on criticism seems to lead to the destruction of creativity, so that people can not make systematic theoretical construction and new practical operation. I think this view is wrong [10]. The more effective way to promote the development of cognition is to put development first and find out the mistakes through strict examination and criticism. The discovery of errors will not hinder the development of cognition. Nothing can promote the emergence of new theories faster than the discovery of errors [11]. In fact, critical thinking and innovation are exist side by side and play a part together [12].

The "Delphi report" puts forward five basic steps of using critical thinking to solve problems, from which we can see that critical thinking does not hinder innovation, on the contrary, it is conducive to innovation, even innovation itself, at least including the elements of innovation.

Step 1: I = identify, that is, find the problem and set the order;

Step 2: $\mathrm{D}=$ determine, that is to determine the relevant information and deepen the understanding;

Step 3: e = enumerate, that is, list the alternatives and predict the consequences;

Step 4: $\mathrm{a}=$ assess, that is, assess the background of the situation and make a preliminary decision;

Step 5: $\mathrm{S}=$ scritinize, that is, to examine the whole process and make necessary self correction [13].

From the perspective of logic, critical thinking and innovative thinking are essentially a kind of cross relationship, and they have both similarities and differences. The common content mainly has the thinking characteristics of logical thinking, skepticism and negation, and has the characteristics of transcendental thinking and their interdependence. The difference lies in their different functions and results.

As a form of thinking, critical thinking and innovative thinking are closely related to logical thinking and contain logical thinking. Critical thinking mainly involves how to properly ask questions, clarify the meaning of language and the structure, evaluation and construction of argument. It is inseparable from logical thinking. As Wang Liwei said: "critical thinking is connected with logic, and logic is the theoretical basis of critical thinking. In other words, critical thinking is related to logic. Logic is the theoretical basis of critical thinking [14]. Creative thinking is also called creative thinking. Generally speaking, it mainly refers to the thinking process of dealing with something or expressing something in a new way on the basis of breaking through the original inherent mode of thinking. Innovative thinking reflects a kind of human creativity, which mainly has the following two aspects: On the one hand, based on the analysis of the existing ideas, and methods, the comprehensive ability of new ideas and new things can be generated through recombination. On the other hand, through the change of point of view, the ability to put forward new solutions, new ideas and new achievements. The essence of creative thinking is a kind of intellectual quality. It is a complex thinking process with initiative and uniqueness, which can grasp the internal essence and law of things development with a new cognitive mode by selecting, breaking through and reconstructing the existing knowledge, experience and newly acquired information in the process of solving problems [15]. It can be seen that creative thinking has gone through two stages: perceptual and rational. On the basis of practice, it has gained perceptual experience about things, and processed perceptual materials to "remove the rough and extract the fine, remove the false and retain the true, from one side to the other, from the outside to the inside", revealing the essence and laws of things, On the basis of grasping the essence and law of things, this paper puts forward creative ideas and thinking process. Creative 
thinking is the result of long-term rational thinking and needs scientific reasoning and demonstration, so it cannot be separated from logical thinking. Therefore, logical thinking is an important part of critical thinking and innovative thinking. Logical thinking plays an indispensable role in the process of critical thinking and innovative thinking.

Critical thinking and innovative thinking have the common features of logical thinking, skepticism, negative thinking and transcendental thinking, which make them interrelated, interdependent and interdependent. The purpose of critical thinking is to produce innovative thinking, which is not satisfied with the status quo. Our analysis, understanding and argumentation evaluation of a thing or thought is not just for the purpose of analysis, understanding for the sake of understanding, and argumentation for the sake of simple evaluation and argumentation. Its ultimate purpose is to produce innovative thinking. Without the production of innovative thinking, critical thinking will become a meaningless way of thinking. Therefore, innovative thinking is the purpose of critical thinking, and critical thinking is to negate the insufficient aspects through analysis, understanding and evaluation, so as to promote the emergence of innovative thinking on the basis of negation.

In the process of thinking, we think critically of the object, but also think creatively. Critical thinking and innovative thinking play different roles in the process of thinking. In the process of thinking, critical thinking mainly plays the role of checking whether the premise is true and questioning, clarifying the premise and evaluating whether the argument is effective. In the process of thinking, innovative thinking mainly plays an innovative role in solving problems, constantly promoting the level of people's understanding of the world to expand to the depth and breadth, and constantly opening up people's spirit of exploration and innovation to unknown areas. Creative thinking is a new and improved way of thinking to solve problems. Critical thinking is a way of thinking that tests the solutions to the problems provided to ensure their effectiveness. It can be seen that the different roles of critical thinking and innovative thinking lead to different results of critical thinking and innovative thinking. Critical thinking is to guide us to doubt and reflect rationally, and cultivate our good thinking quality in terms of clarity, relevance, consistency, legitimacy and predictability. The final result is to lead to innovative thinking [16]. Innovative thinking is to enhance the ability to understand and transform the world, mainly to expand the field of human practical activities, so its final result is to produce new methods, new things and new achievements to solve problems, and finally to make new breakthroughs in the field of practice.

\section{Conclusion}

The direct goal of critical thinking education is to cultivate good critical thinkers, that is, people who can integrate and effectively use various skills of critical thinking, and enhance their self-confidence, self-consciousness and good judgment in using these powerful tools in other disciplines and daily life. Good critical thinkers include not only the dimension of skills, but also the dimension of temperament [17]. Critical thinking should not only answer the questions of the validity of the reasoning form, but also the questions of the authenticity and credibility of the premise of reasoning. That is, critical thinking is concerned with the form and content of thinking at the same time, which is the basic feature of daily thinking [18]. Logic course should make a direct contribution to the realization of the basic educational goal of critical thinking [19].

It can be seen that critical thinking is closely related to logic. In other words, logic science is the theoretical basis of critical thinking. However, it must be noted that here "logic" refers not only to the traditional "narrow sense logic", also known as formal logic, but also to the "broad sense logic" which includes informal logic. It can be seen that correctly dealing with the relationship between logic and critical thinking is of positive significance, whether for doing well in logic or critical thinking. Especially when the teaching and research of critical thinking are gaining momentum in China, it has more important actual value to discuss this issue in depth.

\section{References}

[1] Coon, Dennis and Mitterer, John O, Introduction to Psychology: Gateways to Mind and Behavior. Belmont, CA: Wedsworth. 1995.

[2] Tim van Gelder, Reason: Improving Informal Reasoning Skills, in Proceedings of the Australian Computers in Education Conference, 2000.

[3] Michael Scriven, The Philosophy of Critical Thinking and Informal Logic, in Daniel Fasko, Jr. (Ed), Critical Thinking: Current Research, Theory and Practice, Hamptom Press, Inc., 2003.

[4] Peter A. Facione, Critical Thinking: What It Is and Why It Counts, in Peter A. Facione, Critical Thinking: A Statement of Expert Consensus for Purposes of Educational Assessment and Instruction, the California Academic Press, Millbrae, CA, 1990 .

[5] R. H. Johnson and J. A. Blair, Informal Logic: An Overview. Informal Logic, Vol. 20, No. 2, 2000.

[6] J. E. McPeck, Critical Thinking and Education, New York: St. Martion's Press, 1981.

[7] Cui Qingtian, Wang Zuoli. Informal logic and critical thinking. Social Sciences, 2004 (04): p33.

[8] Xiong Minghui. On the Relationship between Critical Thinking and Logic. Modern Philosophy. 2006 (02): p 115-118.

[9] Robert Cogan, Critical Thinking: Step by Step, University Press of America, Inc., 1998.

[10] Chen Bo. Critical Thinking and Cultivation of Innovative Talents. China University Teaching 2017 (03): p26-27.

[11] Dong Yu. Three Misunderstandings of Critical Thinking, Higher Education Research, 2012 (12): p 1120-1149. 
[12] Chen Bo. Introduction to Logic. Beijing: Beijing Normal University Press, 2007: 313-316.

[13] Xu Ben. Reading Classics: Humanistic Education in American universities. Beijing: Peking University Press, 2015: p15.

[14] Wang Liwei. Research on Applied Logic from the Perspective of Critical Thinking. Beijing: Yanshan University, 2017. p17.

[15] Zhang Xiaomang. On Creative Thinking and Logical Thinking. Zhejiang Academic Journal, 1994 (03): p60.

[16] Xiefrong, Liulifang. On the Relationship and Value of Critical Thinking and Innovative Thinking from the Perspective of
Logic. Journal of Jiujiang University (Social Science Edition), 2020 (01): p81-83.

[17] Wu Hongzhi, Liu Chunjie. Critical thinking: using Argumentation Logic as a tool. Xi'an: Shaanxi people's publishing house, 2005. p46-49.

[18] Liu Ye Tao, Zhang Ya Nan. On the Relationship between Logic and Critical Thinking. Academic Forum. 2007 (03): p 81-83.

[19] Wu Huzhi. On the Adaptation of University Logic Course to Critical Thinking Education. Journal of Hunan University of Science \& Technology (Social Science Edition). 2020 (03): p50. 